\title{
Adrenocortical steroid response to ACTH in different phenotypes of non-obese polycystic ovary syndrome
}

\author{
Nese Cinar, Ayla Harmanci, Duygu Yazgan Aksoy, Kadriye Aydin and Bulent Okan Yildiz
}

\begin{abstract}
Background: Adrenal androgen excess is frequently observed in PCOS. The aim of the study was to determine whether adrenal gland function varies among PCOS phenotypes, women with hyperandrogenism $(H)$ only and healthy women.

Methods: The study included 119 non-obese patients with PCOS (age: $22.2 \pm 4.1 \mathrm{y}, \mathrm{BMI}: 22.5 \pm 3.1 \mathrm{~kg} / \mathrm{m}^{2}$ ), 24 women with $\mathrm{H}$ only and 39 age and BMl- matched controls. Among women with PCOS, 50 had H, oligo-anovulation (O), and polycystic ovaries $(\mathrm{P})(\mathrm{PHO}), 32$ had $\mathrm{O}$ and $\mathrm{H}(\mathrm{OH}), 23$ had $\mathrm{P}$ and $\mathrm{H}(\mathrm{PH})$, and 14 had $\mathrm{P}$ and $\mathrm{O}(\mathrm{PO})$. Total testosterone (T), SHBG and DHEAS levels at basal and serum 17-hydroxprogesterone (17-OHP), androstenedione (A4), DHEA and cortisol levels after ACTH stimulation were measured.

Results: T, FAI and DHEAS, and basal and AUC values for 17-OHP and A4 were significantly and similarly higher in PCOS and $\mathrm{H}$ groups than controls ( $\mathrm{p}<0.05$ for all) whereas three groups did not differ for basal or AUC values of DHEA and cortisol. Three hyperandrogenic subphenotypes (PHO, OH, and $\mathrm{PH}$ ) compared to non-hyperandrogenic subphenotype (PO) had significantly and similarly higher T, FAI, DHEAS and AUC values for 17-OHP, A4 and DHEA $(p<0.05)$. All subphenotypes had similar basal and AUC values for cortisol.

Conclusion: PCOS patients and women with H only have similar and higher basal and stimulated adrenal androgen levels than controls. All three hyperandrogenic subphenotypes of PCOS exhibit similar and higher basal and stimulated adrenal androgen secretion patterns compared to non-hyperandrogenic subphenotype.
\end{abstract}

Keywords: Adrenal androgen, PCOS, ACTH, DHEAS

\section{Introduction}

Polycystic ovary syndrome (PCOS) is the most common endocrine disorder of reproductive-aged women with an estimated prevalence of 6-7\% [1]. PCOS is characterized by androgen excess, oligo-anovulation $(\mathrm{O})$ and polycystic ovaries (P). Since it's a heterogeneous disorder, several criteria have been proposed for its diagnosis [2,3]. According to 1990 National Institutes of Health (NIH) criteria, the presence of both oligo-and/or anovulation and clinical (hirsutism) and /or biochemical signs of hyperandrogenism $(\mathrm{H})$ are needed, regardless of the presence of $\mathrm{P}$ on ultrasound [2]. Due to the lack of agreement

\footnotetext{
*Correspondence: yildizbo@yahoo.com

Endocrinology and Metabolism Unit, Department of Internal Medicine, Hacettepe University School of Medicine Hacettepe, Ankara 06100, Turkey
}$$
\text { Ankara 06100, Turkey }
$$

on standardized criteria to make the diagnosis of PCOS, an international consensus workshop in Rotterdam, sponsored by The American Society for Reproductive Medicine (ASRM) and European Society for Human Reproduction and Embryology (ESHRE) expanded the diagnostic criteria for PCOS with the addition of the ultrasound assesment of ovarian morphology [3]. According to these new criteria, PCOS can be defined when at least two of the three features $(\mathrm{O}, \mathrm{H}$ and $\mathrm{P})$ are present. Using these Rotterdam criteria, four phenotypes of PCOS are identified (i.e.) PHO (phenotype1), $\mathrm{OH}$ (phenotype 2), $\mathrm{PH}$ (phenotype 3) and PO (phenotype 4).

While the ovaries are the main source of androgen excess in PCOS, excess adrenal androgen (AA) levels and adrenocortical dysfunction have been reported in many PCOS patients [4-7]. Elevated serum levels of

Ciomed Central

(c) 2012 Cinar et al.; licensee BioMed Central Ltd. This is an Open Access article distributed under the terms of the Creative Commons Attribution License (http://creativecommons.org/licenses/by/2.0), which permits unrestricted use, distribution, and reproduction in any medium, provided the original work is properly cited. 
dehydroepiandrosterone sulfate (DHEAS) and $11 \beta$ hydroxyandrostenedione (11-OHA4) is found in 20$50 \%$ of patients with PCOS $[4,6]$. PCOS women show a generalized hypersecretion of adrenocortical products, basally and in response to ACTH including pregnenolone, 17-hydroxypregnenolone, dehydroepiandrosterone (DHEA), androstenedione (A4) and possibly cortisol (F) [8].

Peripubertal AA excess is associated with the development of PCOS-like symptomatology in patients with 21hydroxylase deficient classic and non-classic adrenal hyperplasia $[9,10]$. Patients with PCOS have a greater incidence of exaggerated AA secretion during the peripubertal period [11] and patients with premature adrenarche are at higher risk for the development of PCOS [12]. Moreover, women with PCOS exhibit enhanced adrenal androgen production over long time $[13,14]$ and increased DHEAS levels were reported in sisters [15] of PCOS patients suggesting that inheritance plays a significant role in AA secretion of PCOS.

Previous data suggest that adrenocortical excess in PCOS might result in different phenotypic features (e.g. acne) [16]. Recently, differences in metabolic characteristics and basal AA levels of the subphenotypes of PCOS have been reported indicating phenotype $\mathrm{PO}$ as the mildest expression of the PCOS spectrum $[17,18]$. We now hypothesize that AA excess will be less pronounced in the phenotype PO of PCOS and will be more associated with hyperandrogenic phenotypes. To test our hypothesis, we determine the differences in AA production in response to ACTH stimulation among different phenotypes of PCOS according to Rotterdam criteria, women with $\mathrm{H}$ only and healthy women.

\section{Materials and methods Subjects}

A total of 143 consecutive non-obese patients $(\mathrm{BMI}<$ $30 \mathrm{~kg} / \mathrm{m}^{2}$ ), who attended to the Outpatient Clinic of Endocrinology and Metabolism of Hacettepe University between January 12006 and December 312010 were prospectively enrolled in the study. Among the patients, 50 had $\mathrm{H}, \mathrm{O}$ and $\mathrm{P}(\mathrm{PHO}), 32$ had $\mathrm{H}$ and $\mathrm{O}$ without $\mathrm{P}$ $(\mathrm{OH}), 23 \mathrm{had} \mathrm{H}$ and $\mathrm{P}$ with normal menses $(\mathrm{PH}), 14$ had $\mathrm{O}$ and $\mathrm{P}(\mathrm{PO})$ and 24 women with $\mathrm{H}$ only. All patients fulfilled the diagnostic criteria for PCOS according to revised 2003 Rotterdam criteria [3]. H was defined as having hirsutism (modified Ferriman-Gallwey score $\geq 6$ ) and/or a total testosterone $(\mathrm{T})$ and/or free androgen index (FAI) level above the upper 95th percentile of 110 healthy non-hirsute eumenorrheic women. Specifically the upper normal limits were as follows: total T, $60 \mathrm{ng} / \mathrm{dl}$ (2.08 nmol/liter) and FAI, 4.94. Ovulatory dysfunction was defined as menstrual cycles $\geq 35$ or $\leq 23$ days. In patients with hirsutism or $\mathrm{P}$ appearance who had apparently regular menstrual bleeding, luteal phase (Days 21-24) progesterone levels were determined and the threshold for the presence of ovulation was taken as $4 \mathrm{ng} / \mathrm{ml}(12.7 \mathrm{nmol} /$ liter $)$. P was defined as the presence of $\geq 12$ follicles in an ovary measuring 2-9 $\mathrm{mm}$ in diameter and/or increased ovarian volume $(>10 \mathrm{~mL})$ at least in a single ovary [3]. Women with a secondary endocrine disorder, such as hyperprolactinaemia, non-classical form of congenital adrenal hyperplasia, thyroid function disorder and androgen secreting tumors were excluded as suggested [3]. Thirty-nine age- and BMI- matched healthy women without features of $\mathrm{H}, \mathrm{O}$ or $\mathrm{P}$ formed the control group. None of the subjects were taking any hormonal medication including oral contraceptive pills for at least 3 months before the study.

The study was approved by the Local Ethics Committee of the Hacettepe University School of Medicine and informed consent was obtained from all subjects.

\section{Study protocol}

All participants were evaluated by means of a standardized form that includes a medical history and physical examination. Weight, height, waist and hip circumferences (waist: midway between the lower rib margin and the iliac crest, hip: widest circumference over the great trochanters) were measured. The body mass index [BMI; weight (kilograms)/ height (meters) ${ }^{2}$ ] and waist to hip ratio (WHR) were calculated. Hirsutism was evaluated by modified Ferriman-Gallwey scoring (mFG) system.

All subjects were studied during the follicular phase of the menstrual cycle (2-5 days after onset of last spontaneous or progestin-induced menstrual bleeding). Basal blood samples were obtained for hormonal and metabolic parameters. Hormonal and metabolic evaluation included $\mathrm{T}, \mathrm{A} 4, \mathrm{DHEAS}$ and sex hormone-binding globulin (SHBG), fasting plasma glucose (FPG) and insulin. Free androgen index $(\mathrm{FAI}=[$ testosterone $(\mathrm{nmol} / \mathrm{L}) /$ SHBG(nmol/L)]x100) and homeostatic model assesment of insulin resistance (HOMA-IR = [fasting insulin $(\mu \mathrm{U} / \mathrm{ml}) \mathrm{x}$ fasting plasma glucose $(\mathrm{FPG})(\mathrm{mmol} / \mathrm{L})] / 22.5)$ were calculated as previously described [19].

All participants underwent short ACTH stimulation test. $0.25 \mathrm{mg}$ ACTH-(1-24) (Synacthen $0.25 \mathrm{mg} / 1 \mathrm{ml}$; Defiante Farmaceutica, S.A., Portugal) was administered IV over $60 \mathrm{sec}$. and blood samples were drawn for serum F, 17-OHP, A4 and DHEA levels $1 \mathrm{~min}$. before and 30 and $60 \mathrm{~min}$. after ACTH administration. Areas under the curve (AUC), and delta max values for 17-OHP, A4, DHEA and F responses were calculated.

\section{Assays}

Blood samples were taken through venepuncture and centrifuged within $2 \mathrm{~h}$ after withdrawal. Serum was 
stored at $-80^{\circ} \mathrm{C}$ until time of studies. Testosterone and insulin concentrations were measured by chemiluminiscent immunoassay kits (Roche Diagnostics $\mathrm{GmbH}$, Mannheim, Germany). SHBG was measured by using immunoradiometric assay (ZenTech, Angleur, Belgium). Plasma glucose concentration was determined by the glucose oxidase method (Olympus AU 2700, Beckmann, Coulter, Inc., MA, USA). The concentration of DHEAS and A4 were determined by chemiluminiscent immunoassay (Immulite ${ }^{\circledR} 2000$, Los Angeles, USA). Serum DHEA level was measured using a solid phase enzyme-linked immunosorbent assay (DRG Instruments, Marburg, Germany). 17-OHP was measured by radioimmunoassay kit from Immunotech.

\section{Statistical analysis}

Differences in basal characteristics and laboratory data among the groups were analyzed by one-way analysis of variance (ANOVA) and post hoc Tukey test for dual-wise comparisons for normally distributed parameters, and Kruskal-Wallis one-way ANOVA and Mann-Whitney test for dual-wise comparisons for parameters with skewed distribution. By using the trapezoidal method, 17-OHP, A4, DHEA and F responses to ACTH stimulation were expressed as AUC. Pearson/ Spearman correlations were used to examine the relationship between DHEAS levels and fasting insulin and HOMA-IR values. Statistical Package for Social Sciences, version 15.0 (SPSS Inc., Chicago) was used for analyses. Values were described as mean $\pm \mathrm{SD}$ and $P<0.05$ was considered statistically significant.

\section{Results}

The basal characteristics of the PCOS, $\mathrm{H}$ only and control groups are shown in Table 1. No significant difference in the basal characteristics was observed between PCOS and $\mathrm{H}$ only group (Table 1, NS for all). The mean levels of T, FAI and DHEAS were significantly higher in PCOS and $\mathrm{H}$ only group than controls (Table $1, \mathrm{P}<0.001$ for all). There was no significant difference in FPG, fasting insulin and HOMA-IR values among the groups (Table 1, NS for all). Basal, stimulated and AUC values for 17-OHP and A4 were significantly and similarly higher in PCOS and $\mathrm{H}$ only groups than controls (Table $2, \mathrm{P}<0.01$ for all) whereas three groups did not differ for basal, stimulated or AUC values of DHEA and F (Table 2, NS for all). Also, delta max AA responses to ACTH were evaluated and PCOS and $\mathrm{H}$ only group had higher values for $17 \mathrm{OHP}$ and A4 than controls ( $\mathrm{P}<0.05$ for all, data not shown).

Table 3 shows the comparisons of clinical and hormonal characteristics among different phenotypes of PCOS. All the phenotypes had similar mean age, BMI and WHR values (Table 3, NS for all). Within the PCOS group, 3 hyperandrogenic subphenotypes ( $\mathrm{PHO}, \mathrm{OH}$ and $\mathrm{PH}$ ) compared to non-hyperandrogenic subphenotype (PO) had significantly and similarly higher T, FAI, DHEAS (Table 3, $\mathrm{P}<0.001$ for all). While there was no significant difference in FPG levels among the groups (Table 3, NS), a significant difference in fasting insulin levels and HOMAIR values between $\mathrm{PHO}, \mathrm{OH}$ and $\mathrm{PH}$ groups was observed (Table 3, $\mathrm{P}<0.01$ for all). Stimulated and AUC values for 17-OHP and A4 were significantly higher in 3 hyperandrogenic subphenotypes ( $\mathrm{PHO}, \mathrm{OH}$ and $\mathrm{PH}$ ) than nonhyperandrogenic subphenotype (PO) (Table 4, $\mathrm{P}<0.05$ for

Table 1 Baseline clinical and hormonal characteristics of the women with PCOS, women with $\mathrm{H}$ only and control groups

\begin{tabular}{|c|c|c|c|c|}
\hline Parameters & $\begin{array}{c}\text { PCOS } \\
(n=119)\end{array}$ & $\begin{array}{c}H \\
(n=24)\end{array}$ & $\begin{array}{l}\text { Control } \\
(n=39)\end{array}$ & $\begin{array}{l}\mathrm{P} \\
\text { (overall) }\end{array}$ \\
\hline Age (year) & $22.2 \pm 4.1$ & $23.8 \pm 4.9$ & $24.4 \pm 2.9$ & NS \\
\hline BMI $\left(\mathrm{kg} / \mathrm{m}^{2}\right)$ & $22.5 \pm 3.1$ & $22.1 \pm 2.3$ & $21.2 \pm 2.08$ & NS \\
\hline WHR & $0.76 \pm 0.06$ & $0.77 \pm 0.04$ & $0.75 \pm 0.06$ & NS \\
\hline $\mathrm{mFG}$ & $8.7 \pm 5.3^{a}$ & $10.0 \pm 3.4^{a}$ & $0.6 \pm 0.9$ & $<0.001$ \\
\hline Testosterone (ng/dl) & $70.4 \pm 34.5^{a}$ & $70.3 \pm 30.7^{a}$ & $34.9 \pm 11.6$ & $<0.001$ \\
\hline SHBG (nmol/l) & $39.6 \pm 20.7^{a}$ & $32.8 \pm 16.7^{a}$ & $56.5 \pm 29.1$ & $<0.001$ \\
\hline FAI & $8.8 \pm 7.6^{a}$ & $8.5 \pm 4.5^{a}$ & $2.7 \pm 1.6$ & $<0.001$ \\
\hline DHEAS $(\mu \mathrm{g} / \mathrm{dl})$ & $278 \pm 134^{b}$ & $314 \pm 115^{a}$ & $204 \pm 74$ & $<0.001$ \\
\hline FPG (mg/dl) & $82.4 \pm 11.8$ & $81.2 \pm 10.7$ & $83.7 \pm 11.2$ & NS \\
\hline Fasting insulin $(\mu \mathrm{l} \mathrm{U} / \mathrm{ml})$ & $11.1 \pm 5.9$ & $9.2 \pm 3.5$ & $9.4 \pm 3.1$ & NS \\
\hline HOMA-IR & $2.3 \pm 1.3$ & $1.8 \pm 0.7$ & $1.9 \pm 0.7$ & NS \\
\hline
\end{tabular}

Results are expressed as mean \pm SD. NS not significant, $B M I$ body mass index, WHR waist-to-hip ratio, mFG modified Ferriman-Gallwey score, SHBG sex hormonebinding globulin, FAl free androgen index, DHEAS dehydroepiandrosterone sulfate, FPG fasting plasma glucose, HOMA-IR homeostatic model assesment of insulin resistance.

${ }^{\text {a }} \mathrm{P}<0.001$ vs. Control.

${ }^{b} \mathrm{P}<0.01$ vs. Control. 
Table 2 ACTH stimulated hormone levels and their AUC values in patients with PCOS, women with H only and control groups

\begin{tabular}{|c|c|c|c|c|}
\hline Parameters & $\begin{array}{l}\text { PCOS } \\
(n=119)\end{array}$ & $\begin{array}{l}H \\
(n=24)\end{array}$ & $\begin{array}{l}\text { Control } \\
(n=39)\end{array}$ & $\begin{array}{l}\mathrm{P} \\
\text { (overall) }\end{array}$ \\
\hline $\mathrm{DHEA}_{0}$ & $16.7 \pm 7.9$ & $20.7 \pm 8.9$ & $14.5 \pm 5.9$ & NS \\
\hline $\mathrm{DHEA}_{30}$ & $23.8 \pm 6.8$ & $25.2 \pm 6.2$ & $21.5 \pm 6.3$ & NS \\
\hline DHEA $_{60}$ & $25.4 \pm 6.3$ & $26.3 \pm 6.0$ & $24.6 \pm 6.3$ & NS \\
\hline 17-OHP o $(\mathrm{ng} / \mathrm{ml})$ & $1.5 \pm 0.9^{b}$ & $1.6 \pm 0.7^{b}$ & $1.1 \pm 0.7$ & $<0.01$ \\
\hline $17-\mathrm{OHP}_{30}(\mathrm{ng} / \mathrm{ml})$ & $3.5 \pm 1.5^{b}$ & $3.4 \pm 0.9^{c}$ & $2.8 \pm 1.2$ & $<0.01$ \\
\hline $17-\mathrm{OHP}_{60}(\mathrm{ng} / \mathrm{ml})$ & $4.1 \pm 1.7^{b}$ & $3.9 \pm 0.9^{b}$ & $3.2 \pm 1.1$ & $<0.01$ \\
\hline$\overline{A 4_{0}(\mathrm{ng} / \mathrm{ml})}$ & $3.1 \pm 1.5^{a}$ & $3.2 \pm 1.2^{b}$ & $2.2 \pm 0.9$ & $<0.001$ \\
\hline $\mathbf{A 4}_{30}(\mathrm{ng} / \mathrm{ml})$ & $4.0 \pm 1.8^{\mathrm{a}}$ & $4.0 \pm 1.2^{b}$ & $2.8 \pm 0.9$ & $<0.001$ \\
\hline $\mathbf{A 4}_{60}(\mathrm{ng} / \mathrm{ml})$ & $4.3 \pm 1.7^{\mathrm{a}}$ & $4.1 \pm 1.2^{b}$ & $3.1 \pm 0.9$ & $<0.001$ \\
\hline $\mathrm{F}_{\mathbf{0}}(\mu \mathrm{g} / \mathrm{dl})$ & $13.9 \pm 5.8$ & $15.9 \pm 7.6$ & $14.0 \pm 5.4$ & NS \\
\hline$\overline{F_{30}(\mu \mathrm{g} / \mathrm{dl})}$ & $26.5 \pm 5.0$ & $26.2 \pm 5.4$ & $25.9 \pm 4.5$ & NS \\
\hline $\mathbf{F}_{60}(\mu \mathrm{g} / \mathrm{dl})$ & $30.9 \pm 6.1$ & $30.8 \pm 6.4$ & $30.6 \pm 5.0$ & NS \\
\hline $\operatorname{AUC}_{\text {DHEA }}(\mathrm{ng} / \mathrm{ml} \times 60 \mathrm{~min})$ & $1338 \pm 375$ & $1459 \pm 375$ & $1227 \pm 351$ & NS \\
\hline AUC $_{17-O H P}(\mathrm{ng} / \mathrm{ml} \times 60 \mathrm{~min})$ & $190 \pm 80^{b}$ & $183 \pm 44^{b}$ & $148 \pm 60$ & $<0.01$ \\
\hline $\mathrm{AUC}_{\mathrm{A} 4}(\mathrm{ng} / \mathrm{ml} \times 60 \mathrm{~min})$ & $232 \pm 99^{\mathrm{a}}$ & $229 \pm 69^{c}$ & $165 \pm 53$ & $<0.001$ \\
\hline $\mathbf{A U C}_{\mathrm{F}}(\mu \mathrm{g} / \mathrm{dl} \times 60 \mathrm{~min})$ & $1471 \pm 303$ & $1487 \pm 361$ & $1446 \pm 258$ & NS \\
\hline
\end{tabular}

Results are expressed as mean \pm SD. NS not significant, AUC area under the curve, DHEA dehydroepiandrosterone, 17-OHP 17-hydroxyprogesterone, $A 4$ androstenedione, $F$ cortisol.

a $\mathrm{P}<0.001$ vs. Control.

b $\mathrm{P}<0.01$ vs. Control.

c $\mathrm{P}<0.05$ vs. Control.

all). All subphenotypes had similar basal, stimulated and AUC values for $\mathrm{F}$ (Table 4, NS for all). Basal, stimulated and AUC values for DHEA in $\mathrm{OH}$ and $\mathrm{PH}$ groups were significantly higher than those in PO group (Table $4, \mathrm{P}<$ 0.05 for all).
To evaluate the prevalence of AA excess in the study groups, DHEAS levels were log transformed to satisfy the assumption of the normal distribution and the upper 95\% normative value for log DHEAS for control group was calculated. 95th percentile log DHEAS value in the

Table 3 Comparisons of clinical and hormonal characteristics among different phenotypes of PCOS

\begin{tabular}{|c|c|c|c|c|c|}
\hline Parameters & $\begin{array}{l}\text { PHO } \\
(n=50)\end{array}$ & $\begin{array}{l}\mathrm{OH} \\
(n=32)\end{array}$ & $\begin{array}{l}\mathrm{PH} \\
(n=23)\end{array}$ & $\begin{array}{l}P O \\
(n=14)\end{array}$ & $\begin{array}{l}P \\
\text { (overall) }\end{array}$ \\
\hline Age (year) & $22.4 \pm 4.5$ & $22.4 \pm 4.3$ & $22.3 \pm 3.3$ & $20.8 \pm 3.4$ & NS \\
\hline BMI $\left(\mathrm{kg} / \mathrm{m}^{2}\right)$ & $22.6 \pm 3.1$ & $22.7 \pm 3.2$ & $22.1 \pm 2.9$ & $22.5 \pm 4.04$ & NS \\
\hline WHR & $0.78 \pm 0.05$ & $0.77 \pm 0.05$ & $0.75 \pm 0.06$ & $0.77 \pm 0.07$ & NS \\
\hline $\mathrm{mFG}$ & $8.2 \pm 5.0^{\mathrm{a}, *}$ & $10.9 \pm 5.1^{a}$ & $10.6 \pm 3.6^{a}$ & $1.4 \pm 1.7$ & $<0.001$ \\
\hline Testosterone (ng/dl) & $74.8 \pm 37.6^{a}$ & $77.9 \pm 30.8^{\mathrm{a}}$ & $71.7 \pm 29.1^{a}$ & $35.9 \pm 15.7$ & $<0.001$ \\
\hline SHBG (nmol/l) & $39.9 \pm 23.5$ & $36.9 \pm 17.8$ & $38.6 \pm 20.7$ & $46.0 \pm 15.7$ & NS \\
\hline FAI & $9.9 \pm 8.4^{a}$ & $9.6 \pm 8.0^{\mathrm{a}}$ & $8.8 \pm 5.8^{b}$ & $2.8 \pm 1.4$ & $<0.01$ \\
\hline DHEAS $(\mu \mathrm{g} / \mathrm{dl})$ & $277 \pm 127^{b}$ & $312 \pm 140^{b}$ & $294 \pm 136^{b}$ & $174.9 \pm 95.8$ & $<0.01$ \\
\hline FPG $(\mathrm{mg} / \mathrm{dl})$ & $82.0 \pm 12.6$ & $81.4 \pm 11.5$ & $83.1 \pm 9.3$ & $84.9 \pm 14.4$ & NS \\
\hline Fasting insulin $(\mu \mathrm{l} \mathrm{U} / \mathrm{ml})$ & $12.3 \pm 7.5^{c}$ & $11.2 \pm 3.7^{c}$ & $8.2 \pm 4.1$ & $10.2 \pm 4.9$ & $<0.01$ \\
\hline HOMA-IR & $2.6 \pm 1.6^{c}$ & $2.3 \pm 0.8^{c}$ & $1.7 \pm 0.9$ & $2.3 \pm 1.2$ & $<0.05$ \\
\hline
\end{tabular}

Results are expressed as mean \pm SD. NS not significant, $\mathrm{PHO}$ polycystic ovaries, oligo-anovulation and hyperandrogenism, $\mathrm{OH}$ oligo-anovulation and hyperandrogenism, $P H$ polycystic ovaries and hyperandrogenism, $P O$ polycystic ovaries and oligo-anovulation, $B M I$ body mass index, $W H R$ waist-to-hip ratio, $m F G$ modified Ferriman-Gallwey score, SHBG sex hormone-binding globulin, FAl free androgen index, DHEAS dehydroepiandrosterone sulfate, FPG fasting plasma glucose, HOMA-IR homeostatic model assesment of insulin resistance.

a $\mathrm{P}<0.001$ vs. $\mathrm{PO}$.

${ }^{\mathrm{b}} \mathrm{P}<0.01$ vs. $\mathrm{PO}$.

${ }^{c} \mathrm{P}<0.01$ vs. $\mathrm{PH}$

${ }^{*} \mathrm{P}=0.05$ vs. $\mathrm{OH}$ 
Table 4 ACTH stimulated hormone levels and their AUC values among different phenotypes of PCOS

\begin{tabular}{|c|c|c|c|c|c|}
\hline Parameters & $\begin{array}{l}\text { PHO } \\
(n=50)\end{array}$ & $\begin{array}{l}\mathrm{OH} \\
(n=32)\end{array}$ & $\begin{array}{l}\mathrm{PH} \\
(n=23)\end{array}$ & $\begin{array}{l}P O \\
(n=14)\end{array}$ & $\begin{array}{l}P \\
\text { (overall) }\end{array}$ \\
\hline DHEA $_{0}$ & $15.9 \pm 7.9$ & $19.3 \pm 7.7^{\mathrm{a}}$ & $17.2 \pm 7.3^{b}$ & $12.2 \pm 7.5$ & $<0.05$ \\
\hline $\mathrm{DHEA}_{30}$ & $23.7 \pm 6.7^{b}$ & $24.9 \pm 6.7^{a}$ & $25.5 \pm 5.5^{a}$ & $18.2 \pm 6.4$ & $<0.05$ \\
\hline $\mathrm{DHEA}_{60}$ & $24.7 \pm 6.3^{*}$ & $27.2 \pm 5.9^{b}$ & $26.3 \pm 5.2$ & $21.8 \pm 8.1$ & $<0.05$ \\
\hline $17-\mathrm{OHP}_{0}(\mathrm{ng} / \mathrm{ml})$ & $1.6 \pm 1.1$ & $1.4 \pm 0.7$ & $1.6 \pm 1.3$ & $0.9 \pm 0.3$ & 0.078 \\
\hline 17-OHP $30(\mathrm{ng} / \mathrm{ml})$ & $3.7 \pm 1.7^{b}$ & $3.7 \pm 1.2^{a}$ & $3.6 \pm 1.5^{b}$ & $2.6 \pm 1.1$ & $<0.05$ \\
\hline 17-OHP 60 (ng/ml) & $4.3 \pm 1.9$ & $4.2 \pm 1.5$ & $4.3 \pm 1.8$ & $3.1 \pm 1.1$ & 0.072 \\
\hline $\mathbf{A} \mathbf{4}_{\mathbf{0}}(\mathrm{ng} / \mathrm{ml})$ & $3.4 \pm 1.9$ & $3.2 \pm 1.2$ & $2.8 \pm 0.8$ & $2.2 \pm 1.0$ & NS \\
\hline $\mathbf{A 4}_{30}(\mathrm{ng} / \mathrm{ml})$ & $4.3 \pm 2.0^{\mathrm{a}}$ & $4.3 \pm 1.8^{b}$ & $4.0 \pm 1.3^{b}$ & $2.9 \pm 0.9$ & $<0.05$ \\
\hline $\mathbf{A 4}_{60}(\mathrm{ng} / \mathrm{ml})$ & $4.7 \pm 1.9^{\mathrm{a}}$ & $4.3 \pm 1.7^{b}$ & $4.4 \pm 1.4^{\mathrm{a}}$ & $3.1 \pm 1.0$ & $<0.01$ \\
\hline$F_{0}(\mu \mathrm{g} / \mathrm{dl})$ & $14.4 \pm 6.3$ & $14.6 \pm 6.0$ & $13.9 \pm 5.6$ & $11.6 \pm 4.4$ & NS \\
\hline $\mathbf{F}_{30}(\mu \mathrm{g} / \mathrm{dl})$ & $26.2 \pm 4.6$ & $28.6 \pm 5.1$ & $25.9 \pm 6.1$ & $25.2 \pm 4.6$ & NS \\
\hline $\mathrm{F}_{60}(\mu \mathrm{g} / \mathrm{dl})$ & $30.4 \pm 6.7$ & $32.3 \pm 5.7$ & $31.5 \pm 5.9$ & $29.5 \pm 5.5$ & NS \\
\hline $\mathbf{A U C}_{\text {DHEA }}(\mathrm{ng} / \mathrm{ml} \times 60 \mathrm{~min})$ & $1314 \pm 390$ & $1437 \pm 348^{a}$ & $1415 \pm 297^{a}$ & $1057 \pm 397$ & $<0.05$ \\
\hline AUC $_{17-O H P}(\mathrm{ng} / \mathrm{ml} \times 60 \mathrm{~min})$ & $198 \pm 90^{\mathrm{a}}$ & $195 \pm 62^{\mathrm{a}}$ & $194 \pm 85^{b}$ & $140 \pm 51$ & $<0.05$ \\
\hline $\mathrm{AUC}_{\mathrm{A} 4}(\mathrm{ng} / \mathrm{ml} \times 60 \mathrm{~min})$ & $254 \pm 117^{a}$ & $240 \pm 93^{b}$ & $230 \pm 69^{a}$ & $164 \pm 55$ & $<0.05$ \\
\hline $\mathbf{A U C}_{\mathrm{F}}(\mu \mathrm{g} / \mathrm{dl} \times 60 \mathrm{~min})$ & $1466 \pm 312$ & $1563 \pm 298$ & $1456 \pm 331$ & $1372 \pm 253$ & NS \\
\hline
\end{tabular}

control group was found as 2.54. The prevalence rates of supranormal DHEAS levels were $27.6 \%$ in PCOS, $33.3 \%$ in $\mathrm{H}$ only group and $2.6 \%$ in the control group respectively. PCOS and $\mathrm{H}$ only groups had significantly higher rates of AA excess than controls $(27.6 \%, 33.3 \%$ and $2.6 \%$ respectively; $\mathrm{P}<0.05$ ) while the two groups did not differ in comparison. Among the PCOS phenotypes, $\mathrm{PHO}$ and $\mathrm{OH}$ group had non-significantly higher rates of AA excess than non-hyperandrogenic subphenotype (PO) (PHO $31.3 \%$ vs $\mathrm{PO} 7.1 \% \mathrm{P}=0.09 ; \mathrm{OH} 34.4 \%$ vs $\mathrm{PO} 7.1 \% \mathrm{P}=$ 0.073 ) whereas no significant difference was observed between $\mathrm{PH}$ and PO group (22.7\% vs $7.1 \%$ respectively, NS).

DHEAS levels did not show any correlation with fasting insulin or HOMA-IR values in PCOS, $\mathrm{H}$ only or control groups or in subphenotype groups of PCOS (NS, data not shown).

\section{Discussion}

In this study, we report adrenocortical steroid response to ACTH among patients with different phenotypes of PCOS according to Rotterdam criteria, women with $\mathrm{H}$ only and healthy women. Our data indicate that nonobese patients with PCOS and women with $\mathrm{H}$ only have similar adrenal responses that differ from age- and BMImatched healthy women with higher basal DHEAS, and higher 17-OHP and A4 levels both basally and in response to ACTH. Even though hyperandrogenism was defined by the presence of hirsutism and/or increased
FAI in this study, all three hyperandrogenic subphenotypes exhibited similar AA secretion patterns with higher DHEAS, and higher 17-OHP and A4 responses to ACTH stimulation compared to non-hyperandrogenic subphenotype. Similar basal DHEA levels in PCOS, $\mathrm{H}$ only and control women despite higher DHEAS values in PCOS and $\mathrm{H}$ only groups compared to healthy women might suggest differences in the expression of DHEA-sulfotransferase activity.

Adrenarche is the maturation of the zona reticularis of the adrenal gland with increase in AAs in early puberty. Premature and/or exaggerated adrenarche is reported to be associated with the development of PCOS in a number of studies [20,21]. Regarding the role of AAs in the pathophysiology of PCOS, adrenal function during childhood and pubertal development in daughters of women with PCOS was studied [22]. In this study, increased DHEAS serum concentrations and biochemical evidence of an exacerbated adrenarche was observed in daughters of women with PCOS suggesting these features as an early step in the development of PCOS [22]. Moreover, adrenocortical excess in PCOS might result in different phenotypic features (e.g.acne) [16]. It is also important to note that the alterations in androgen levels with aging in PCOS might result in changes in phenotypic expression of the syndrome (i.e. decrease in prevalence of hyperandrogenic phenotypes) [23]. Our data suggest that hyperandrogenic subphenotypes of PCOS have increased 
prevalence of AA excess in the form of circulating DHEAS levels and higher AA response to ACTH stimulation compared to non-hyperandrogenic subphenotype. Taken together, it might be postulated that the subjects who exposed to premature and/or exaggerated adrenarche during pubertal development might present with hyperandrogenic phenotypes of PCOS later in life and AAs might play role in the clinical presentation and phenotypic expression of PCOS.

Enhanced secretory response of A4, 17-OHP and DHEA after ACTH stimulation in women with PCOS defined by NIH criteria was shown in the previous studies [24-26]. Conflicting results are also available even in studies using the same NIH criteria $[27,28]$. For example, Erel et al. showed that AA response to ACTH was similar between women with PCOS and controls [27], whereas Kamel et al. reported that PCOS patients $(\mathrm{n}=29)$ had higher basal and stimulated DHEAS, 17$\mathrm{OHP}$ and stimulated $\mathrm{F}$ levels than idiopathic hirsutism $(\mathrm{IH})(\mathrm{n}=21)$ and control $(\mathrm{n}=20)$ subjects [28]. Evaluating potential differences of AA excess among various PCOS subphenotypes we now provide data supporting the hypothesis that AA excess both basally and in reponse to ACTH is more associated with hyperandrogenic PCOS and is not a prominent feature of the phenotype formed by ovulatory dysfunction and polycystic ovaries. Our data are in line wih previous work in that basal and stimulated cortisol levels in PCOS are similar with healthy women [29]. Furthermore, cortisol responses to ACTH appear to be similar in subphenotypes of PCOS as well.

Prevalence of AA excess defined by supranormal DHEAS levels in PCOS is between 20-30\% . Carmina et al. reported similar prevalence of AA excess determined by elevations of DHEAS in idiopathic hyperandrogenism (IHA), classic PCOS and ovulatory PCOS (PH) $(48.3 \%, 36.7 \%$ and $29.1 \%$ respectively, NS) [30]. We have found similar rates of AA excess in PCOS, $\mathrm{H}$ only patients and among hyperandrogenic phenotypes of PCOS (PHO, OH, $\mathrm{PH}$ ).

IHA, a diagnosis exclusion, is the second most common androgen disorder. Adrenal hyperandrogenism is common in these patients. Almost $50 \%$ of the patients with IHA were reported to have elevated circulating DHEAS levels [30]. An isolated increase of DHEAS levels was found in $7 \%$ of the patients and ovarian source of the androgens was found in $90 \%$ of the patients associated with exaggerated AA production in about half of them [30,31]. Atmaca et al. showed that peak and AUC responses of 11-deoxy-cortisol, DHEAS and A4 to ACTH were significantly higher in IHA patients than controls [32]. These data are in line with our finding of similar adrenal hyperfunction in PCOS and $\mathrm{H}$ only groups that were higher than controls.
Comparison of endocrine and metabolic characteristics of the different phenotypes of PCOS were studied in several studies $[17,18,33,34]$. Panidis et al. reported that circulating androgens were higher in PCOS patients with hyperandrogenic subphenotypes ( $\mathrm{PHO}, \mathrm{OH}$ and $\mathrm{PH}$ ) compared with those with non-hyperandrogenic subphenotype (PO) [17]. Kauffman et al. also showed that testosterone and DHEAS levels were highest in PHO and $\mathrm{OH}$ phenotype and the androgen levels were indistinguishable in PO than controls [33]. These results suggest that androgen production is the most prominent endocrine and metabolic factor differentiating phenotypic expressions of PCOS and phenotype PO is the mildest expression of the PCOS spectrum. In accordance with these data, we have found that AA excess both basally and in response to $\mathrm{ACTH}$ was less pronounced in the phenotype PO of PCOS and more associated with hyperandrogenic phenotypes.

Conflicting data are available regarding potential interaction between glucose/insulin axis and adrenocortical dysfunction in PCOS. Hyperinsulinemia in PCOS stimulates androgen secretion by ovarian theca cells and increases the hormonally active free androgen fraction by reducing the hepatic production of SHBG [35]. Insulin sensitizing agents such as metformin causes a decrease in serum androgen levels with improvement in insulin sensivity parameters [36]. In a study including 1212 women with PCOS and 254 healthy women, phenotype $\mathrm{PHO}$ was found to be associated with more IR than other phenotypes [17]. Obese patients with $\mathrm{OH}$ and PO phenotype were also characterized with IR whereas phenotype $\mathrm{PH}$ was not associated with IR. No significant association was reported between DHEAS levels and fasting insulin in some studies [37] whereas high DHEAS levels were reported to be negatively correlated to insulin resistance in others [16,38,39]. Moreover, it was demonstrated that hyperinsulinemia potentiates ACTH-stimulated androgen production in women with PCOS [40]. Regarding the association between insulin resistance and hyperandrogenism, studies with insulin sensitizers such as thiazolidinediones or metformin showed that significant reductions were observed in the secretion of A4 and 17-OHP in response to ACTH stimulation $[41,42]$. On the other hand, adrenocortical biosynthesis, basally and in response to ACTH, are thought to be associated with glucose-mediated glucose disposal rather than the degree of hyperinsulinemia or insulin-mediated glucose disposal [43]. In our study, we have failed to show any difference in insulin resistance parameters between PCOS patients and controls, and a relationship between DHEAS levels and fasting insulin or HOMA-IR values. Normal BMI and relatively young age of the participants might in part explain our finding of a non-significant difference in fasting insulin and 
HOMA-IR values between patients and controls. Alternatively, we might have failed to detect a difference due to insensitivity of the fasting measurements we have used. Obesity may affect adrenocortical function by decreasing insulin sensitivity and inducing the secretion of adipocytokines. Available literature suggests that hypersecretion of F and possibly A4 and DHEA are observed in obese healthy women [44] although conflicting results are also reported [45]. Our study design precludes us from any potential confounding effect of obesity since only lean women participated in the study.

A limitation of our study is the relatively small sample size of the groups with each phenotype. Secondly, we were not able to assess potential ovarian contribution to androgen synthesis since we did not use a GnRH analogue. Thirdly, our results could not be extrapolated to obese women with PCOS or PCOS patients of different races.

In conclusion, our data suggest that in PCOS patients and women with $\mathrm{H}$ only, basal and $\mathrm{ACTH}$-stimulated AA levels are similar and higher than those in healthy women. All three hyperandrogenic subphenotypes of PCOS exhibit similar and higher basal and ACTHstimulated AA secretion patterns compared to nonhyperandrogenic subphenotype. AA excess appears to be more associated with hyperandrogenism and is less pronounced in women with ovulatory dysfunction and polycystic ovaries. Similar AA production in women with $\mathrm{H}$ only and hyperandrogenic subphenotypes of PCOS suggest that this group might be a spectrum of PCOS and might develop the syndrome at a later time. Understanding the regulation of adrenal steroidogenesis in subphenotypes of PCOS might provide novel mechanistic insights into the pathophysiology and developmental context of the syndrome.

\section{Competing interests}

The authors declare that they have no competing interests.

\begin{abstract}
Authors' contribution
NC: contributed to acquisition, analysis and interpretation of the data, and drafting the article. AH: contributed to acquisition of the data, and critical revision of the paper. DYA: contributed to acquisition of the data, and critical revision of the paper. KA: contributed to acquisition of the data, and critical revision of the paper. BOY: contributed to conception and design, acquisition, analysis and interpretation of the data, and critical revision of the
\end{abstract} paper. All authors read and approved the final manuscript.

Received: 29 October 2012 Accepted: 29 November 2012 Published: 7 December 2012

\section{References}

1. Azziz R, Woods KS, Reyna R, Key TJ, Knochenhauer ES, Yildiz BO: The prevalence and features of the polycystic ovary syndrome in an unselected population. J Clin Endocrinol Metab 2004, 89:2745-2749.

2. Zawadski JK, Dunaif A: Diagnostic criteria for polycystic ovary syndrome: towards a rational approach. In Current Issues in Endocrinology and Metabolism. Edited by. Boston MA: Blackwell; 1992:377-384.

3. Rotterdam ESHRE/ASRM-Sponsored PCOS Consensus Workshop Group: Revised 2003 consensus on diagnostic criteria and long term health risks related to polycystic ovary syndrome. Fertil Steril 2004 81:19-25.

4. Hoffman DI, Klove K, Lobo RA: The prevalence and significance of elevated dehydroepiandrosterone sulfate levels in anovulatory women. Fertil Steril 1984, 42:76-81.

5. Steinberger E, Smith KD, Rodriguez-Rigau L: Testosterone, dehydroepiandrosterone, and dehydroepiandrosterone sulfate in hyperandrogenic women. J Clin Endocrinol Metab 1984, 59:471-477.

6. Carmina E, Rosato F, Janni A: Increased DHEAs levels in PCO syndrome: evidence for the existence of two subgroups of patients. J Endocrinol Invest 1986, 9:5-9.

7. Hague WM, Honour JW, Adams J, Vecsei P, Jacobs HS: Steroid responses to ACTH in women with polycystic ovaries. Clin Endocrinol (Oxf) 1989, 30(4):355-365.

8. Yildiz BO, Azziz R: The adrenal and polycystic ovary syndrome. Rev Endocr Metab Disord 2007, 8:331-342.

9. Dewailly D, Vantyghem-Haudiquet MC, Sainsard C, Buvat J, Cappoen JP, Ardaens K, Racadot A, Lefebvre J, Fossati P: Clinical and biological phenotypes in late-onset 21-hydroxylase deficiency. J Clin Endocrinol Metab 1986, 63:418-423.

10. Moran C, Azziz R, Carmina E, Dewailly D, Fruzzetti F, Ibanez L, Knochenhauer ES, Marcondes JA, Mendonca BB, Pignatelli D, Pugeat M, Rohmer V, Speiser PW, Witchel SF: 21-Hydroxylase-deficient nonclassic adrenal hyperplasia is a progressive disorder: a multicenter study. Am J Obstet Gynecol 2000, 183:1468-1474.

11. Lobo RA, Goebelsmann U, Horton R: Evidence for the importance of peripheral tissue events in the development of hirsutism in polycystic ovary syndrome. J Clin Endocrinol Metab 1983, 57:393-397.

12. Ibanez L, Potau N, Zampolli M, Street ME, Carrascosa A: Girls diagnosed with premature pubarche show an exaggerated ovarian androgen synthesis from the early stages of puberty: evidence from gonadotropin-releasing hormone agonist testing. Fertil Steril 1997, 67:849-855.

13. Puurunen J, Piltonen T, Jaakkola P, Ruokonen A, Morin-Papunen L, Tapanainen JS: Adrenal androgen production capacity remains high up to menopause in women with polycystic ovary syndrome. J Clin Endocrinol Metab 2009, 94:1973-1978.

14. Yildiz BO, Woods KS, Stanczyk F, Bartolucci A, Azziz R: Stability of adrenocortical steroidogenesis over time in healthy women and women with polycystic ovary syndrome. J Clin Endocrinol Metab 2004, 89:5558-5562.

15. Yildiz BO, Goodarzi MO, Guo X, Rotter Jl, Azziz R: Heritability of dehydroepiandrosterone sulfate in women with polycystic ovary syndrome and their sisters. Fertil Steril 2006, 86:1688-1693.

16. Chen MJ, Chen CD, Yang JH, Chen CL, Ho HN, Yang WS, Yang YS: High serum dehydroepiandrosterone sulfate is associated with phenotypic acne and a reduced risk of abdominal obesity in women with polycystic ovary syndrome. Hum Reprod 2011, 26:227-234.

17. Panidis D, Tziomalos K, Misichronis G, Papadakis E, Betsas G, Katsikis I, Macut D: Insulin resistance and endocrine characteristics of the different phenotypes of polycystic ovary syndrome: a prospective study. Hum Reprod 2012, 27:541-549.

18. Zhang HY, Zhu FF, Xiong J, Shi XB, Fu SX: Characteristics of different phenotypes of polycystic ovary syndrome based on the Rotterdam criteria in a large-scale Chinese population. BJOG 2009, 116:1633-1639.

19. Yildiz BO, Bozdag G, Harmanci A, Otegen U, Boynukalin K, Vural Z, Kirazli S, Haznedaroglu IC, Yarali H: Increased circulating soluble P-selectin in polycystic ovary syndrome. Fertil Steril 2010, 93:2311-2315.

20. Ibanez L, Potau N, Virdis R, Zampolli M, Terzi C, Gussinye M, Carrascosa A, Vicens-Calvet E: Postpubertal outcome in girls diagnosed of premature pubarche during childhood: increased frequency of functional ovarian hyperandrogenism. J Clin Endocrinol Metab 1993, 76:1599-1603.

21. Lucky AW, Rosenfield RL, McGuire J, Rudy S, Helke J: Adrenal androgen hyperresponsiveness to adrenocorticotropin in women with acne and/or hirsutism: adrenal enzyme defects and exaggerated adrenarche. J Clin Endocrinol Metab 1986, 62:840-848.

22. Maliqueo M, Sir-Petermann T, Perez V, Echiburu B, de Guevara AL, Galvez C, Crisosto N, Azziz R: Adrenal function during childhood and puberty in daughters of women with polycystic ovary syndrome. J Clin Endocrinol Metab 2009, 94:3282-3288.

23. Panidis D, Tziomalos K, Macut D, Delkos D, Betsas G, Misichronis G, Katsikis I: Cross-sectional analysis of the effects of age on the hormonal, 
metabolic, and ultrasonographic features and the prevalence of the different phenotypes of polycystic ovary syndrome. Fertil Steril 2012, 97(2):494-500.

24. Azziz R, Black V, Hines GA, Fox LM, Boots LR: Adrenal androgen excess in the polycystic ovary syndrome: sensitivity and responsivity of the hypothalamic-pituitary-adrenal axis. J Clin Endocrinol Metab 1998, 83:2317-2323.

25. Wu XK, Zhou SY, Sallinen K, Pollanen P, Erkkola R: Ovarian-adrenal cross-talk in polycystic ovary syndrome: evidence from wedge resection. Eur J Endocrinol 2000, 143:383-388.

26. Rosenfield RL, Mortensen M, Wroblewski K, Littlejohn E, Ehrmann DA: Determination of the source of androgen excess in functionally atypical polycystic ovary syndrome by a short dexamethasone androgen-suppression test and a low-dose ACTH test. Hum Reprod 2011, 26(11):3138-3146.

27. Erel $C T$, Senturk LM, Oral E, Colgar U, Ertungealp E: Adrenal androgenic response to 2-hour ACTH stimulation test in women with PCOS. Gynecol Endocrinol 1998, 12:223-229.

28. Kamel N, Tonyukuk V, Emral R, Corapcioglu D, Bastemir M, Gullu S: Role of ovary and adrenal glands in hyperandrogenemia in patients with polycystic ovary syndrome. Exp Clin Endocrinol Diabetes 2005, 113:115-121.

29. Carmina E, Lobo RA: Pituitary-adrenal responses to ovine corticotropinreleasing factor in polycystic ovary syndrome and in other hyperandrogenic patients. Gynecol Endocrinol 1990, 4:225-232.

30. Carmina E, Lobo RA: Prevalence and metabolic characteristics of adrenal androgen excess in hyperandrogenic women with different phenotypes. J Endocrinol Invest 2007, 30:111-116.

31. Siegel SF, Finegold DN, Lanes R, Lee PA: ACTH stimulation tests and plasmadehydroepiandrosterone sulfate levels in women with hirsutism. N Engl J Med 1990, 323(13):849-854

32. Atmaca H, Tanriverdi F, Unluhizarci K, Bayram F, Kelestimur F: Investigation of adrenal functions in patients with idiopathic hyperandrogenemia. Eur J Endocrinol 2006, 155:307-311.

33. Kauffman RP, Baker TE, Baker VM, DiMarino P, Castracane VD: Endocrine and metabolic differences among phenotypic expressions of polycystic ovary syndrome according to the 2003 Rotterdam consensus criteria. Am J Obstet Gynecol 2008, 198:670. e671-677; discussion 670 e677-610.

34. Orio F, Palomba S, Colao A: Cardiovascular risk in women with polycystic ovary syndrome. Fertil Steril 2006, 86(Suppl 1):S20-S21.

35. Dunaif A: Insulin resistance and the polycystic ovary syndrome: mechanism and implications for pathogenesis. Endocr Rev 1997, 18(6):774-800.

36. Palomba S, Falbo A, Russo T, Manguso F, Tolino A, Zullo F, De Feo P, Orio F Jr: Insulin sensitivity after metformin suspension in normal-weight women with polycystic ovary syndrome. J Clin Endocrinol Metab 2007, 92(8):3128-3135.

37. Kauffman RP, Baker VM, DiMarino P, Castracane VD: Hyperinsulinemia and circulating dehydroepiandrosterone sulfate in white and Mexican American women with polycystic ovary syndrome. Fertil Steril 2006, 85:1010-1016.

38. Brennan K, Huang A, Azziz R: Dehydroepiandrosterone sulfate and insulin resistance in patients with polycystic ovary syndrome. Fertil Steril 2009, 91:1848-1852

39. Lerchbaum E, Schwetz V, Giuliani A, Pieber TR, Obermayer-Pietsch B: Opposing effects of dehydroepiandrosterone sulfate and free testosterone on metabolic phenotype in women with polycystic ovary syndrome. Fertil Steril 2012, 98(5):1318-1325.

40. Lanzone A, Fulghesu AM, Guido M, Fortini A, Caruso A, Mancuso S: Differential androgen response to adrenocorticotropic hormone stimulation in polycystic ovarian syndrome: relationship with insulin secretion. Fertil Steril 1992, 58:296-301.

41. Guido M, Romualdi D, Suriano R, Giuliani M, Costantini B, Apa R, Lanzone A: Effect of pioglitazone treatment on the adrenal androgen response to corticotrophin in obese patients with polycystic ovary syndrome. Hum Reprod 2004, 19(3):534-539.

42. la Marca A, Morgante G, Paglia T, Ciotta L, Cianci A, De Leo V: Effects of metformin on adrenal steroidogenesis in women with polycystic ovary syndrome. Fertil Steril 1999, 72(6):985-989.

43. Farah-Eways L, Reyna R, Knochenhauer ES, Bartolucci AA, Azziz R: Glucose action and adrenocortical biosynthesis in women with polycystic ovary syndrome. Fertil Steril 2004, 81(1):120-125.
44. Komindr S, Kurtz BR, Stevens MD, Karas JG, Bittle JB, Givens JR: Relative sensitivity and responsivity of serum cortisol and two adrenal androgens to alpha-adrenocorticotropin-(1-24) in normal and obese, nonhirsute, eumenorrheic women. J Clin Endocrinol Metab 1986, 63:860-864.

45. Vicennati V, Calzoni F, Gambineri A, Gagliardi L, Morselli Labate AM, Casimirri F, Pasquali R: Secretion of major adrenal androgens following ACTH administration in obese women with different body fat distribution. Horm Metab Res 1998, 30:133-136.

doi:10.1186/1757-2215-5-42

Cite this article as: Cinar et al:: Adrenocortical steroid response to ACTH in different phenotypes of non-obese polycystic ovary syndrome. Journal of Ovarian Research 2012 5:42.

\section{Submit your next manuscript to BioMed Central and take full advantage of:}

- Convenient online submission

- Thorough peer review

- No space constraints or color figure charges

- Immediate publication on acceptance

- Inclusion in PubMed, CAS, Scopus and Google Scholar

- Research which is freely available for redistribution 